\title{
Challenges and effectiveness of eclectic method at higher secondary level in rural Bangladesh
}

\author{
Md. Morshedul Alam \\ Department of English Language and Literature \\ International Islamic University Chittagong (IIUC), Bangladesh \\ Tanzin Sultana \\ Department of English, BGC Trust University Bangladesh, Bangladesh
}

\begin{abstract}
This article addresses the challenges and effectiveness of implementing Eclectic Method in Language Teaching at higher secondary level in the rural context of Bangladesh. This paper adopts a qualitative approach, and six rural colleges are selected to conduct the research. These institutions are located in Chittagong District, Bangladesh. Ten English teachers were interviewed face-to-face to collect data about the challenges they have faced and the effectiveness they observed in applying Eclectic Approach in their colleges. The findings show the applicability of Eclectic Approach in several ways that include flexibility in teaching, variety in adapting language teaching aspects, allowing new ideas, dynamic classroom facilities, enhancing teachers' and students' respect for cross-culture and multi-lingual classroom. The findings indicate some hurdles in teaching English that include lack of trained teachers, improper text books, teachers' insufficient knowledge, rigid mentality of the rural teachers, insufficient infrastructural facilities, and taking pride in mother-language etc. This research may help the policy makers of language and curriculum design in developing effective strategies for Eclectic practices in rural Bangladesh.
\end{abstract}

Keywords Implementation, Eclectic Approach, Higher Secondary Level, Rural Areas, Challenges and Effectiveness.

Paper type Research paper

\section{Background to the study}

A lot of approaches and methods like GTM (Grammar-Translation Method), Direct Method, Audio-Lingual, and CLT (Communicative Language Teaching) were mostly introduced in the world as effective ways of English language teaching with the passage of time. GTM is a way of teaching a second or foreign language where students only learn and memorize grammatical rules accurately so that they can read the foreign or second language-based texts in the target language. The oldest method GTM was applied in early 1500AD to teach Greek and Latin for communication. While Latin was being

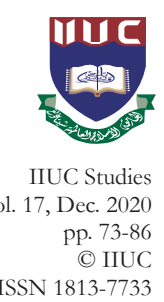




\section{IIUC Studies, 17}

obsolete almost, English replaced it to be taught in this method. At the end of the eighteenth century this method was introduced in Prussia to publish two books for the secondary level: a French course-book by Johann Valentine Meidinger in 1783 and an English course-book by Johann Christian Fick in 1793. Gradually, this method became developed and prominent in whole Europe and in Bangladesh in the nineteenth and the twentieth centuries.

In language teaching when GTM failed to accomplish the needs and requirements of language policy makers, in the $20^{\text {th }}$ century American linguists applied a behavioral approach, similar to Direct Method, (insisting on demonstration and action) Audio-Lingualism where teachers focus on grammar through drill and practice. Krashen (1982) points out the failure of the method by saying that this teaching approach did not produce the desired result as learners were unable to speak fluently the target language as the focal point was only the understanding of forms and not the meaning. On the other hand, in the method of Audio-Lingualism, emphasis is given on the target language rather than the native one where each of the communicative skills, i.e., listening, reading, writing and speaking is taught separately. Later in 1950's due to scientific tenability this method is criticized by the critics, particularly by Noam Chomsky.

After 1960 when researchers focused on the efficiency and performance in learning second language, Communicative Language Teaching (CLT) was considered most cohesive and socio-cognitive methodology in teaching English in the classroom. "There are rules of use without which the rules of grammar would be useless" (Hymes, 1972). During 1970's some ELT teachers and educationists in North-America and also in Europe commenced using CLT with the purpose of enhancing students' skills in communication (Savignon, 1987). CLT concentrates on practical learning in the classroom by acquiring not only the methods but also the aims, and the truth is that the competence of communication develops the skills in manifestation, exposition and speaking of the real substance (Savignon, 2008). Through classroom activities like debate, extempore speech, interview, pair work, group work, sharing opinions among students, CLT method in contrast to the previous approaches emphasizes the verbal aspect of pedagogy to acquire the target language in order to promote competence in real life communication in the students. In spite of its influence on the field of language teaching, CLT method was questioned by some critics. According to Michael Swan (1985), in this method the theoretical understanding and the practical understanding differ a lot. Another critic Elaine Ridge (2013) 
marked that though CLT claimed to facilitate communicative competence in students, a student proficient in a language might not make full use of the target language especially if the target one was dead language. Some critics of CLT also note that since in the classroom CLT approach gives importance to learners' communicative skill rather than grammatical and structural accuracy, in practical field, the learners' grammatically incorrect utterance might lead to misconception.

Nunan (1991) correctly remarks that there would never be a correct method at all because gradual changes in language teaching methods imply that no method is hundred percent effective and perfect in a particular situation. Since each method has its own limitations beside its utility, it is not possible for a particular method to achieve all language goals and program objectives. Since a language cannot be taught without good command of grammar, vocabulary, pronunciation, and understanding and finally of creating fruitful communication, Eclectic Method is the method that meets the expectations and desires of the language policy makers and curriculum designers. In language teaching, Eclectic Approach is a kind of knowledge of different theories for particular cases. Eclectic Method is a recognizant multitude of various approaches and methods: Grammar-Translation, Audio-Lingual and Communicative Language Teaching to ensure students' abilities and goals of teaching. Kumar (2013) notes, "the eclectic method is a combination of different methods of teaching and learning approaches."

To Larsen-Freeman (2004), Eclectic Method refers to a pluralistic, extensive, comprehensive and all-encompassing approach of both teaching and learning where the principal strategies of implementing different pedagogic approaches are combined methodically and rationally to meet the manifold and clear needs and expectations of students. This approach having multicolor blossoms emphasizes the aims of the learner's abilities. This teaching method does rely not only on a single pattern or model but it also combines various skills and principles.

Even though in 1970's and in 1980's Eclectic Approach was recommended as a backwash to the quantities of teaching English language, in the beginning of 1990 it was advocated for academic purposes. Since Eclectic Approach is a standard method of several concepts, ideas, theories and styles, Rivers (1981) advocates that an Eclectic Method concedes a language teacher in classroom "to absorb the best techniques of all the well-known language teaching methods into their classroom procedures, using them for the purposes for which they are most appropriate."

In Bangladesh, English teaching is compulsory from primary level to 
higher secondary level and at tertiary levels it is also compulsory except in the dept. of English. For a long time, GTM survived with its limitations in the classrooms of Bangladesh. Due to global acceptance of CLT for second language acquisition, Bangladesh initiated CLT in 1990. In 2001, Bangladesh government included CLT as an effective methodology in the curriculum design produced by National Curriculum Textbook Board (NCTB) from class six to twelve to improve the learners' competence in real life communication. In reality, the mission of CLT failed to achieve its vision in our country. Students cannot communicate effectively outside the classroom in real life due to untrained teachers' inability to sort out the inconsistency between the ideology of CLT and its implementation in real life. Moreover, "CLT in our country cannot be implemented properly due to varied constraints, such as enormous class size, inadequacy of logistic supports, teachers' preference for traditional teaching methods, mismatch between curriculum and assessment, poor socio-economic condition, cultural differences and the like (Al-Mamum \& Jakir, 2017)."

Since, the limitations of GTM and CLT in effective language teaching and learning are undeniable in Bangladesh especially in the rural context; Eclectic Method with different principles of different methods can face the contextual realities. The paper focuses on applying Eclectic Method at college level in the context of rural Bangladesh. It aims to stimulate the language policy makers and curriculum designers in developing teaching strategy effectively by Eclectic Approach which they may employ by overcoming its challenges.

\section{Literature review}

After 1970 in Bangladesh CLT assured just communicative competence through teaching English in communicative style in the classroom, but its outcome is not up to the mark. Alam (2016) in his research paper points out some challenges: insufficient trained teachers, influence of local culture on foreign language teaching, improper language policy and language testing etc. Thus, in Bangladesh context, Alam (2016) agrees with Ali and Walker (2014) that inconsistency and incoherence in language teaching process, and insufficient cooperation and coordination among different stakeholders are also barriers in facilitating the benefits of CLT in the classroom. So, due to CLT's being an insufficient approach and failure to meet the demand of effective language teaching, Eclectic Method has become a recent phenomenon in Bangladesh. Many researchers have been inspired by this approach. On applying Eclectic Approach in EFL context, Chaudhury and 
Karim (2014) remark, "possibly the implementation of eclectic approaches or combinations of methods may be appropriate in Bangladesh context." Moreover, the language teachers have to specify their roles as well as they have to reconsider themselves to be designers and coordinators of English language teaching in place of imposing authoritarian rule in the classroom. Besides, learners should not act in the classroom passively rather they have to play active role in the classroom.

This outcome-based learning needs a comprehensive and diversified teaching approach. Brown (2000) says that for developing communication skills, a single teaching approach or method cannot be efficacious as well as practical as the needs and questions of learners have multiplied. Preferably to face the distinctive needs of learners and to develop their ample fluency in the skills of communication, an adaptable and many-sided approach is needed. It can thoroughly access the matter and approach the view with various theories for different cases.

Tabassum (2018) remarks in her paper that for achieving the targets of the lesson, numerous researchers encourage teachers to adapt the Eclectic Method to teaching for developing communication skills. Only by acquiring reading and writing skills, an effective communication cannot be maintained. For this, in an authentic setting the classroom activities need to be focused, designed, practiced and evaluated more competently (Chan, 2011). Divsar and Tahriri (2009) have shared their experience that the learners who were taught in Eclectic methodology, showed more enhancement in their communication skills in and outside classrooms better than those who were taught in any particular single method. Kim and Kim (2005) also view that Eclectic Approach sustains the learners' convenience to develop their respective creativities and mature their understanding of the rules of the grammar of the target language.

In teaching a foreign language at higher secondary level in rural Bangladesh, language teachers have to adopt a constructive approach like Eclectic Method involving various strategies because the rural students even at higher secondary level have poor understanding capacity due to socio-economic condition, and an inappropriate ratio of classroom size and students within a fixed time. So, $\mathrm{Li}$ (2012) notes that the curriculum designed for the English Language Association in UNAF hoped for the learners' interest to receive more information, save the information as well as their capacity to implement the information in a real context in proper time. Weideman (2001) remarks, "today, many good teachers use it proudly as a tag to describe their teaching, wearing it almost like a badge of honour." Kumar 


\section{IIUC Studies, 17}

(2013) also comments, "Language should not be separated into chunks like pronunciation, grammar and vocabulary." Here, Bishop and Verleger (2013) define that the technical method Eclectic can ascertain the learning process and make students comfortable in participating in the classroom also by making them work in pairs or in groups to share previously gained knowledge so that they can assist one another to achieve a higher perception of a subject.

Nunan (2001) suggests that teachers should teach "language in ways that make form relationship transparent." Billah (2015) noted that Eclectic Method is the combination of the strength of various methods, competences and pedagogies. In this concept teachers must be multi-dimensional in thinking and in receiving the change with open mind. Teachers also need to keep the knowledge of different methods and approaches so that they can bring the methods together in a combination to use in the classroom. Sometimes, keeping the approaches, methods and models synchronically, in any way, may not give the required results an English language teacher is looking for. So, language teachers need to have suitable and preceding knowledge of distinctive methodologies to make proper utilization of the Eclectic Method.

In rural areas, even at the higher secondary level any single approach like GTM, CLT or Audio-Lingual Method fails to make students communicative as these particular methods are unable to give situational chunks in learning. So, it is seen that rural learners are supposed to learn English not for communication purpose rather to be certified for a degree to ensure their livelihood and social status. So, for effective teaching, the rural teachers have to advocate Eclectic Method to attach life to the concepts learnt in classrooms. In this regard, the teachers have to ensure four types of communicative competences- socio-linguistic competence, discourse competence, grammar competence and strategic competence to make a flow in communicative processing (Dawkins, 1986).

Moreover, Gilliland, James, and Bowman (1994) justify the Eclectic Method over the deficiency of the particular method because each particular method is based on a narrow particular theory and has limited scope to explore. Duncum (2004) says that while teaching in the classroom, the meaning of the idea can be understood through an interaction of a song, the spoken voice, acoustic effects, language and images. According to Gao (2011), Eclectic Method combines the four skills of English language: listening, speaking, reading and writing, and adds some rules in the classroom. All the same, Mwanza (2017) outlines the effectiveness with 
challenges of the Eclectic Approach in the following way,

"...one of the premises of eclecticism is that teaching should serve learners not methods. Thus, teachers should feel free in choosing techniques and procedures inside the classroom. There is no ideal approach in language learning. Each one has its merits and demerits. There is no loyalty to certain methods. Teachers should know that they have the right to choose the best methods and techniques in any method according to learners' needs and learning situation. Teachers can adopt a flexible method and technique so as to achieve their goals. They may choose whatever works best at a particular time in a particular situation."

Research questions

a. What problems do you find in teaching CLT?

b. What can be the solution to overcome the existing method in rural Bangladesh?

Methodology

This research is genuinely a qualitative approach where data were collected through interview.

\section{Method}

This paper follows a qualitative approach where the secondary data were collected through interviews. Six colleges of rural areas in Chittagong, Bangladesh have been visited by the researchers physically. Ten higher secondary level language teachers have been interviewed face to face by the researchers.

\section{Instruments}

As it is a qualitative approach, the researchers prepare a written questionnaire consisting of two questions for interview. The language teachers of the higher secondary level have been asked the same questions to generate data. Later the data have been analyzed and discussed.

Data analysis

While implementing the Eclectic Approach, the English teachers find effectiveness and they also encounter challenges. The data were collected through face-to-face interview from ten rural English teachers of higher secondary level and analyzed in line with the qualitative method. For 
presenting and analyzing the data, the teachers are coded as T1, T2, and T3...T10.

T-1, while teaching in CLT method in the colleges of the rural areas faces many problems, he strongly believes that curriculum design is not compatible with CLT. He also thinks that in the present syllabus design, students' skill evaluation is not proportionate. Importance is given much too writing test whereas speaking test counts very poor little.

T-2 points out that the rural students enter the higher secondary level with insufficient knowledge of English from the secondary school. As a result, their skills in English are not satisfactory. T-2 also points out that Education Boards encourage the teachers to give more marks to the students than they actually deserve in their answer scripts. So, sometimes the teachers evaluate answer scripts by students' good handwriting and not by the language of the answer.

T-3 says that in the existing curriculum students do not pay attention to study rather they want to pass the examination easily without study. What T-3 says is also supported by T-1. T-3 also supports that there are no good training systems for the teachers. He suggests that Eclectic Approach should be useful for the rural Bangladeshi students, as in this method students' capability is evaluated in a friendly environment.

T-4 agrees with T-1 that syllabus is exam oriented instead of developing communication skills in real life situation. He adds that there is no oral testing or examining communication ability in this prevalent language teaching approach. He further adds that just fixed question samples are set for classes and examinations, where teachers have little scope to bring new dimensions in teaching students outside these question patterns.

T-5 gives the opinion that still in rural areas English learning means only the conventional form of memorizing selected grammar rules and examples to pass of the examination. For example, he says that the same rules of articles are taught from grade 3 to 12 , and in completing sentences, students use the same sentences as examples. For example, in the use of 'so that' rule, from the 6th grade they have been writing the same sentences in the same way using no new phrases, or words. Since they are unable to produce various sentences, they cannot communicate in real life context. Like T-1, he also says that students' speaking skill is below standard as speaking is not focused in the examination like reading and writing skills.

T-6 notes another point. In the colleges of rural areas, teacher-students ratio: class sizes, lack of institutional supports are responsible for the failure of the CLT method in teaching. He also opines that no language method will 
government encourages multi-media classroom teaching, but this digital project also fails in rural Bangladesh as there are not enough modern technological supports. Like T-1, he says that CLT cannot assure the development of potential improvement in communication skill as marks are based on theoretical aspects (writing) in lieu of listening and speaking.

T-7 firmly believes that the writing skill of the students of the rural areas at the higher secondary level is quite frustrating. According to him the main factor is lack of teachers' sincerity to adopt any new language learning approach. Here, he supports T-5 and adds that the principal object of the learners of the rural areas is to achieve a good GPA without developing proper knowledge of English.

According to T-8, the rural students should be motivated to watch English films, debates, hear songs, news and talk shows in English so that curiosity in knowing and achieving knowledge about English culture and tradition is created in them. The teacher also notes that when a teacher's strength depends on teaching the students effectively with a fixed method, he can strengthen it by applying a new method according to the students' needs. In this case the Eclectic Method is necessary to fit our rural students to increase competence in English. But he also says that in the rural areas, applying the Eclectic Approach is more challenging as the rural students are less talented than the urban ones.

T-9 points out the issue that the duration of class time is very limited. Even a trained teacher cannot create proper interaction with students. He also points out that language teachers are in a hurry to complete the syllabus without putting due emphasis on the understanding abilities of the students. In this context, he strongly supports T-6 and adds that class size must be minimized from the existing scenario so that within the fixed time teachers can create proper interaction among the students in classroom activities.

T-10 shares his classroom experience stating that students are found having Anglo-phobia of learning English as it is their second language. So, they do not feel confident in reading or writing English as much as they feel in the case of Bangla. Students feel shy in classroom activities. This fear demotivates them in developing skills in English. He also agrees with T-6 and T-9 about the imbalanced teacher-student ratio, scarcity of modern technological devices like lab, computers or multimedia projectors, etc. As a solution he also opines that the Eclectic Method may bring necessary positive impacts on English language teaching and learning at the rural higher secondary level in Bangladesh. 


\section{Research limitation}

This paper focuses on six rural colleges located in the rural areas of Chittagong District of Bangladesh. The data may not present the scenario of whole Bangladesh. There are enough scopes to carry on further research in this field.

\section{Utilities of eclectic method}

a. Teachers may shape their method according to circumstances and realistic situations in the classroom.

b. Students will have the opportunities to practice both GTM and CLT methods. It will develop not only understanding power but also memorizing ability.

c. Teachers are independent enough to involve learners in the activities in the classroom like idea exchanging, group work, language workshop, and role paly etc.

d. Four English proficiency skills namely listening, speaking, reading, and writing, are equally practiced and emphasized.

e. Teachers can adapt the best ideas to exercise as different strategies constitute this flexible method.

f. This method reduces the detachment and dullness in facilitating multi-tasks to make the classroom environment dynamic.

g. Because of using different teaching strategies, in the Eclectic Method learners develop more understanding and memorizing abilities than in CLT and GTM.

h. This teaching approach creates a high interaction between language practitioners and students that motivates the learners to be confident and efficient in learning the target language.

i. In this approach, classes often become participatory, reciprocal, lively and student-centered.

j. This method contributes much to making learners extrovert and enthusiastic in classroom activities.

k. In this method, students can nurture and employ both analyzing power and creative faculty, and this is how they can enhance their pedagogic skill in language learning.

\section{Problems in implementing eclectic method}

a. Combining different approaches may cause conflict in language teaching and learning where students may fail to adapt both methods simultaneously.

b. Due to lack of proper training, language teachers may face difficulties in 
teaching the Eclectic Method.

c. Insufficient text books and lack of curriculum and syllabus regarding the Eclectic Approach may create hurdles in the application of the Eclectic Method.

d. Lack of audio-visual classroom, uninterrupted electricity supply and inadequacy of institutional and logistic support may be the obstacles in this regard.

e. Large classroom size consisting of 40 or above students is a potential impediment to implementing this approach.

f. Poor socio-economic background of the students can be a hurdle to materialize this method.

g. Students are reluctant to learn in any method perfectly: rather they are very much prone to achieve a good GPA.

h. This method does not give directions about any specific analysis in selecting various principles of various methods.

i. The existing curriculum and syllabus is not up to the mark to satisfy the learners achieving linguistic skills.

j. In Bangladesh the language teachers in rural areas are reluctant to accommodate and apply any new approach in teaching.

\section{Research findings}

a. Equal emphasis must be put on four skills such as, listening, speaking, reading, and writing.

b. Monitoring from rightful authority related to implementing the Eclectic Method in language teaching must be ensured.

c. Using digital devices such as smart phone, computer, laptop, tab, projector, and sound proof classroom should be available.

d. Teachers must be motivated to change their rigid mentality and they should be provided with good instruction and training regarding the Eclectic Approach.

e. Unusual class size must be minimized to the moderate number of 30 (thirty) students.

f. Anglophobia must be removed and students should be extrovert.

g. Standard and up to date text books, following Eclectic Approach must be written and the curriculum and syllabus must be redesigned in line with the Eclectic Method. 


\section{Conclusion}

In Bangladesh, Bengali is considered L1 and English is thought often as L2 or foreign language. In addition, the standard of education is not up to the mark: however, the status of the teaching of English at every level is frustrating. Higher secondary level is one of the prime levels of a student to acquire knowledge and skills, but English teaching at this level is still not modernized in keeping with the pace of the advanced world. This research focuses on the necessity of improving the present English teaching method at higher secondary level and also provides some effective suggestions in this regard. This research will also contribute a lot to the implementation of the Eclectic Approach at the higher secondary level in the context of rural Bangladesh. The current English teaching method at the higher secondary level needs much improvement and reform to satisfy the desires of the learners. The ELT practitioners will get guidelines here as to how to improve their teaching strategies. It is hoped that the learners will be highly benefitted by the use of the Eclectic Method in their English language learning. Moreover, this research may be an eye opener for stakeholders, educationists and policy makers to draw up the national policy of English teaching for the higher secondary level students in the rural Bangladesh.

\section{References}

Alam, M. M. (2016). Challenges in implementing CLT at secondary schools in rural Bangladesh. IIUC Studies, 13, 93-102.

Ali, M. M., \& Walker, A. L. (2014). Bogged down ELT in Bangladesh: Problems and policy. English Today, 30(2), 30-36.

Al-Mamun, M., \& Jakir. (2017). Advocacy of eclectic approach to ESL/EFL teaching in Bangladesh. Jagannath University Journal of Arts, 7(1), 122-130.

Billah, M. (2015, February 13). Eclectic approach to teaching language. The Daily Observer. Retrieved from http:/ / www.observerbd.com/2015/02/13/72233.php

Bishop, J. L., \& Verleger, M. A. (2013, June). The flipped classroom: A survey of the research. In ASEE National Conference Proceedings, Atlanta, GA, $30(9), 1-18$.

Brown, H. D. (2000). Principles of language learning and teaching. 10 Bank St, United States: Pearson Education.

Chan, V. (2011). Teaching oral communication in undergraduate sciences: Are we doing enough and doing it right? Journal of Learning Design, 4(3), 71-79.

Chaudhury, T. A., \& Karim, M. Z. (2014). CLT approach in developing English reading skills in tertiary levels in Bangladesh. Asian Journal of 
Education and e-Learning, 2(1), 47-55.

Dawkins, R. (1986). The blind watchmaker. United Kingdom: Norton \& Company Inc.

Divsar, H., \& Tahriri, A. (2009). Investigating the effectiveness of an integrated approach to teaching literature in an EFK context. Journal of Pan-Pacific Association of Applied Linguistics, 13(2), 105-116.

Duncum, P. (2004). Visual culture isn't just visual: Multiliteracy, multimodality and meaning. Studies in Art Education, 45(3), 252-264.

Gao, L. (2011). Eclecticism or principled eclecticism. Creative Education, 2(4), 363-369.

Gilliland, B. E., James, R. K., \& Bowman, J. T. (1994). Response to the Lazarus and Beutler's article on technical eclecticism. Journal of Counseling and Development, 72(5), 554-555.

Hymes, D. H. (1972). On communicative competence. In J. B. Pride, \& J. Holmes, Sociolinguistics selected readings (Ed.). Harmondsworth: Penguin.

Kim, Y., \& Kim, J. (2005). Teaching Korean writing class: Balancing the Process and Genre Approach. Asian EFL Journal Quarterly, 7(2), 69-90.

Krashen, S. (1982). Principles and practice in second language acquisition. Oxford: Pergamon.

Kumar, C. P. (2013). The eclectic method: Theory and its application to the learning of English. International Journal of Scientific and Research Publications, 3(6), 1-4.

Larsen-Freeman, D. (2004). Teaching and principles in language teaching (Ed.). Delhi, India: Oxford University Press.

Li, W. (2012). An eclectic method of college English teaching. Journal of Language Teaching and Research, 3(1), 166-171.

Mwanza, D. S. (2017). The eclectic approach to language teaching: Its conceptualizations and misconceptions. International Journal of Humanities Social Sciences and Education, 4(2), 53-67.

Nunan, D. (1991). Language teaching methodology. London: Prentice-Hall.

Nunan, D. (2001). Tradition and Change in the ELT Curriculum. Plenary Presentation at $3^{\text {rd }}$ International Symposium on ELT in Beijing, China.

Tabassum, P. (2018). Effect of the eclectic approach of teaching on English communication skills at Elementary Level. Modern Journal of Language Teaching Methods (MJLTM), 8(6), 138-146.

Ridge, E. (2013). Communicative language teaching: Some of the challenges for teacher trainers in South Africa. Per Linguam, 10(1), 29-40.

Rivers, W. M. (1981). Teaching foreign language skills. Chicago: University of Chicago Press. 
Savignon, S. J. (1987). Communicative language teaching. Theory Into Practice, $26(4), 235-242$.

Savignon, S. J. (2008). Interpreting communicative language teaching: Contexts and concerns in teacher education (Ed.). New Haven: Yale University Press.

Swan, M. (1985). A critical look at the communicative approach. ELT Journal, $39(1), 2-12$.

Weideman, A. (2001). The old and the new: Reconsidering eclecticism in language teaching. Linguam, 17(1), 1-13.

\section{Corresponding Author}

Md. Morshedul Alam can be contacted at: morshedeng82@gmail.com 